\title{
Effects of prepartum fat supplementation on plasma concentrations of glucagon-like peptide-1, peptide $Y Y$, adropin, insulin, and leptin in periparturient dairy cows
}

\author{
Rizaldy C. Zapata, ${ }^{* 1}$ Reza Salehi, $\dagger^{1}$ Divakar J. Ambrose, $† \ddagger$ and Prasanth K. Chelikani ${ }^{\star} \S^{2}$ \\ ${ }^{*}$ Department of Production Animal Health, Faculty of Veterinary Medicine, University of Calgary, 3330 Hospital Drive NW, Calgary, \\ Alberta T2N 4N1 Canada \\ †Department of Agricultural, Food and Nutritional Science, University of Alberta, 410 Agriculture/Forestry Centre, Edmonton, \\ Alberta T6G 2P5 Canada \\ łLivestock Research Branch, Alberta Agriculture and Rural Development, 7000113 Street NW, Edmonton, Alberta T6H 5T6 Canada \\ $\S$ Gastrointestinal Research Group, Snyder Institute for Chronic Diseases, University of Calgary, 3330 Hospital Drive NW, Calgary, \\ Alberta T2N 4N1 Canada
}

\begin{abstract}
Dietary fat supplementation during the periparturient period is one strategy to increase energy intake and attenuate the degree of negative energy balance during early lactation; however, little is known of the underlying hormonal and metabolic adaptations. We evaluated the effects of prepartum fat supplementation on energy-balance parameters and plasma concentrations of glucagon-like peptide-1, peptide tyrosine-tyrosine (PYY), adropin, insulin, leptin, glucose, nonesterified fatty acid, and $\beta$-hydroxybutyric acid in dairy cows. Twenty-four pregnant dairy cows were randomized to diets containing either rolled canola or sunflower seed at $8 \%$ of dry matter, or no oilseed supplementation, during the last $5 \mathrm{wk}$ of gestation and then assigned to a common lactation diet postpartum. Blood samples were collected at $-2,+2$, and $+14 \mathrm{~h}$ relative to feeding, at 2 wk after the initiation of the diets, and at 2 wk postpartum. Dietary canola and sunflower supplementation alone did not affect energy balance, body weight, and plasma concentrations of glucagon-like peptide-1, PYY, adropin, insulin, leptin, nonesterified fatty acid, and $\beta$-hydroxybutyric acid; however, canola decreased and sunflower tended to decrease dry matter intake. We also observed that the physiological stage had a significant, but divergent, effect on circulating hormones and metabolite concentrations. Plasma glucagon-like peptide-1, PYY, adropin, nonesterified fatty acid, and $\beta$-hydroxybutyric acid concentrations were greater postpartum than prepartum, whereas glucose, insulin, leptin, body weight, and energy balance were greater prepartum than postpartum. Furthermore, the
\end{abstract}

Received December 24, 2014

Accepted June 8, 2015.

${ }^{1}$ Both authors contributed equally to this work.

${ }^{2}$ Corresponding author: pchelika@ucalgary.ca interaction of treatment and stage was significant for leptin and adropin, and tended toward significance for PYY and insulin; only insulin exhibited an apparent postprandial increase. Postpartum PYY concentrations exhibited a strong negative correlation with body weight, suggesting that PYY may be associated with body weight regulation during the transition period. These novel findings demonstrate that the transition from pregnancy to lactation is a stronger determinant of circulating gut hormone concentrations than dietary lipid in transition dairy cows.

Key words: glucagon-like peptide-1, peptide YY, adropin, dairy cow, dietary fat

\section{INTRODUCTION}

The transition period, which brackets 3 wk on either side of calving, is associated with tremendous metabolic and hormonal adaptations in dairy cows. The transition cows experience a rapid shift from positive energy balance during the dry period to a protracted state of negative energy balance in early lactation due primarily to the inability of energy intake to compensate for the energy demands of lactation (Drackley, 1999). The relative energy deficiency of early lactation is associated with intense mobilization of lipid reserves and excessive ectopic hepatic lipid deposition, which in turn leads to hepatic lipidosis, ketosis, and other metabolic disorders (Goff and Horst, 1997). To limit such metabolic disorders, various dietary strategies are used - one of which is dietary lipid supplementation in an attempt to improve energy intake, with consequent benefits on production and reproductive performances (Drackley, 1999). The majority of the studies with dietary fat involve supplementation from early through late lactation for evaluating productive and reproductive performance (Staples et al., 1998; Loften et al., 
2014). Dietary lipid supplementation prepartum has been shown to decrease DMI prepartum but increase milk yield postpartum (Karimian et al., 2015), decrease the interval to first ovulation (Colazo et al., 2009), and decrease liver triglycerides (Petit et al., 2007). However, little is known of the effects of prepartum fat supplementation on hormonal and metabolic adaptations during the periparturient period.

The enteroendocrine cells of the gut secrete a multitude of hormones that play key roles in digestive functions as well as in regulating energy balance. Some of these anorexigenic hormones in monogastrics include the distal intestinal L cell products glucagon-like peptide-1 (GLP-1; encoded by proglucagon gene) and peptide tyrosine-tyrosine (PYY; Karra and Batterham, 2010). Apart from the intestine, the liver is also a rich source of anorexigenic hormones among which adropin has been shown to play a key role in improving insulin sensitivity, glucose metabolism, and hepatic steatosis in mice (Kumar et al., 2008). We previously demonstrated that the mRNA for proglucagon and PYY are expressed in the bovine gut with increasing abundance from the proximal to the distal intestine (Pezeshki et al., 2012). Among the macronutrients, lipids are potent secretagogues of GLP-1, PYY, and adropin in monogastrics (Kumar et al., 2008; Dong and Brubaker, 2012). Feeding rumen-inert fats (calcium salts of long-chain FA), or abomasal infusion of polyunsaturated fats enriched in oleic, linoleic, or linolenic acids (e.g., canola oil, soybean oil), has been shown to increase the expression and secretion of anorexigenic hormones such as cholecystokinin (Chelikani et al., 2004; Bradford et al., 2008) and GLP-1 (Relling and Reynolds, 2007a,b; Bradford et al., 2008; Relling and Reynolds, 2008) together with a reduction in DMI in lactating cows. However, data is limited on the changes in gut hormones during the pre- and postpartum periods in dairy cows.

Plasma concentrations of cholecystokinin, GLP-1 and glucose dependent insulinotropic peptide were reported to be greater postpartum than prepartum in Holstein cows (Relling and Reynolds, 2007b; Larsen et al., 2010; Hayirli et al., 2011), whereas insulin and leptin concentrations were greater pre- compared with postpartum (Liefers et al., 2003; Kokkonen et al., 2005; Afzalzadeh et al., 2010). However, little is known of the effects of prepartum high fat diets on gut hormone concentrations. Dietary fat supplementation prepartum has been shown to have no effect on plasma cholecystokinin (Hayirli et al., 2011) but decrease plasma leptin concentrations (Afzalzadeh et al., 2010); it is unknown whether other hormones are similarly modulated. Therefore, the objectives of this study were to determine the effects of prepartum dietary fat supplementation on plasma concentrations of GLP-1, PYY, adropin, insulin, and leptin during the pre- and postpartum periods and to assess whether these hormones are correlated with various parameters including DMI, BW, BCS, energy balance, and metabolites.

\section{MATERIALS AND METHODS}

\section{Animals, Husbandry, and Diets}

The study was conducted at the Dairy Research and Technology Centre, University of Alberta. Protocols used in this study were approved by the University Animal Policy and Welfare Committee, and the cows were cared for in compliance with Canadian Council on Animal Care (CCAC, 1993). Twenty-four pregnant Holstein dairy cows (8 primiparous and 16 multiparous) housed in a group pen during early dry period were housed in individual tie stalls during the last 5 wk of gestation and after calving. The cows had ad libitum access to fresh drinking water and feed. From 5 wk prepartum, the cows were randomly assigned to receive 1 of 3 diets that were formulated to meet the nutrient requirements of dry cows (NRC, 2001) and supplemented with rolled canola seed (CAN), rolled sunflower seed (SUN), or no oilseed supplementation (CON) until calving (Table 1). Canola and sunflower seed were added to adjust the total dietary fat content of the ration to $8 \%$ on DM basis, which was similar to the fat levels that we reported previously (Colazo et al., 2009). After calving, all cows were assigned to a single lactation diet $\left(\mathrm{NE}_{\mathrm{L}}=1.63 \mathrm{Mcal} / \mathrm{kg}\right)$ containing on a DM basis barley silage (24.1\%), alfalfa silage $(20.9 \%)$, alfalfa hay $(7 \%)$, ground barley grain $(7.1 \%)$, rolled barley $(12 \%)$, rolled corn $(7.2 \%)$, wheat dried distillers grain $(4.8 \%)$, canola meal $(7.4 \%)$, soybean meal $(0.4 \%)$, poultry tallow (1.3\%), Megalac (1.1\%; Church and Dwight Co. Inc., Princeton, NJ), molasses $(0.8 \%)$, and vitamins and minerals $(1.9 \%)$. Each day, fresh feed were measured and offered at $0800 \mathrm{~h}$ and the orts collected, weighed, and recorded $24 \mathrm{~h}$ later to calculate intake on an as-fed basis. Feed samples were taken weekly from forage and concentrates to evaluate feed DM. Rations were adjusted weekly based on DM content. The cows were milked twice daily between 0400 and $0600 \mathrm{~h}$ and between 1530 and $1730 \mathrm{~h}$. Milk production was automatically recorded at each milking, and milk samples were collected only during the second week postpartum from Tuesday p.m. to Friday a.m. to evaluate milk composition for energy-balance calculations. Energy balance at 2 wk after the initiation of the diets and 2 wk postpartum were calculated as previously described (Rabelo et al., 2003). The body 
Table 1. Ingredients and nutrient composition of the prepartum diets

\begin{tabular}{lccc}
\hline Item & Control $(\mathrm{CON})$ & Canola $(\mathrm{CAN})$ & Sunflower $(\mathrm{SUN})$ \\
\hline Ingredient composition $(\%$ of DM) & & & \\
Barley silage & 60.0 & 60.0 & 60.0 \\
Alfalfa hay & 10.0 & 10.0 & 10.0 \\
Ground barley & 10.0 & 10.0 & 10.0 \\
Soybean hulls & 10.0 & 6.2 & 3.4 \\
Canola meal & 5.0 & 0.8 & 0.0 \\
Canola seed & 0.0 & 0.0 & 8.0 \\
Sunflower seed & 0.0 & 5.0 & 5.0 \\
Vitamins, minerals & 5.0 & 13.8 & 14.4 \\
Nutrient composition (\% of DM) & 14.2 & 41.3 & 40.1 \\
CP & 42.0 & 7.4 & 6.2 \\
NDF & 2.7 & 1.6 & 1.5 \\
Crude fat & 1.4 & & \\
Net energy (Mcal/kg) & & \\
\hline
\end{tabular}

weights were obtained at the start of the study before the animals were randomized into different groups, at calving, and at $35 \mathrm{~d}$ postpartum. The prepartum body weights, before initiation of dietary treatments, were similar among treatments $(\mathrm{CON}=679 \pm 22 \mathrm{~kg}$; CAN $=664 \pm 29 \mathrm{~kg} ; \mathrm{SUN}=612 \pm 31 \mathrm{~kg})$. Together with weight measurements, BCS were determined using a scale from 1 (thin) to 5 (obese; Edmonson et al., 1989).

\section{Sample Collection}

Blood samples were collected from the tail vein at +14 (2200 $\mathrm{h}$ of the previous day), $-2(0600 \mathrm{~h})$, and $+2 \mathrm{~h}(1000 \mathrm{~h})$ relative to feeding from all the cows at 2 wk after the introduction of the diets, and again at 2 wk postpartum. We previously reported that plasma concentrations of the prototypical gut satiety peptide cholecystokinin, as well as the metabolic hormones leptin and IGF-1, remain elevated for at least $12 \mathrm{~h}$ after feeding or abomasal infusion of canola oil, which is suggestive of a lack of distinct postprandial surges for these hormones (Chelikani et al., 2004). Therefore, in the current study, we predicted a similar response and restricted our blood sampling to 3 time points. The samples were collected on ice in tubes containing EDTA (Vacutainer, Becton Dickinson and Co., Franklin Lakes, NJ) and centrifuged within $2 \mathrm{~h}$ at $4^{\circ} \mathrm{C}$ for $15 \mathrm{~min}$ at $3,300 \times \mathrm{g}$. Plasma was separated and immediately transferred to tubes containing a cocktail of enzyme inhibitors [DPP-IV inhibitor $(10 \mu \mathrm{L} / \mathrm{mL}$ blood; Cat. \# DPP4-010, Millipore Corporation, Temecula, $\mathrm{CA})$ and protease inhibitors $(10 \mu \mathrm{L} / \mathrm{mL}$ blood; Cat. \# P2714, Sigma-Aldrich, St. Louis, MO)] and stored at $-80^{\circ} \mathrm{C}$ until analysis. An additional set of samples for metabolite analyses was also collected at similar times $(2200,0600$, and $1400 \mathrm{~h})$ on the same days as above. These samples were collected in heparinized tubes (Vacutainer) and centrifuged, plasma was harvested, and a pooled sample was prepared by mixing equal quantities of plasma from the 3 collections, which was stored at $-20^{\circ} \mathrm{C}$ until analysis for NEFA, BHBA, and glucose.

\section{Assays}

The plasma concentrations of GLP-1, PYY, adropin, insulin, and leptin were measured using commercially available ELISA kits. All assays were subjected to validation procedures using pooled bovine plasma. Each sample was run in duplicates using the manufacturers' recommended protocols.

The GLP-1 assay cross reacts with human, bovine, guinea pig, mouse, and rat GLP-1 (7-36) amide with a range of 0.30 to $3,000 \mathrm{pmol} / \mathrm{L}$ (S-1359, Bachem Americas Inc., Torrance, CA). Addition of 189 and 625 pmol/L for GLP-1 to pooled plasma in 3 independent assays yielded mean recoveries of 113 and $102 \%$, respectively. Parallelism was assessed by serial dilutions of bovine plasma (1:2 to 1:16) using 3 pooled samples. Linear regression of expected versus measured concentrations for GLP-1 yielded average slope of $0.91, \mathrm{R}^{2}$ values $(P<0.001)$ of 0.98 , and Y-intercept of 0.77 . The intraassay and interassay coefficients of variation for GLP-1 were 5.18 and $4.9 \%$, respectively, and assay sensitivity was $2.33 \mathrm{pmol} / \mathrm{L}$.

Plasma PYY concentrations were measured using an assay that only cross reacts with PYY $(1-36)$ and PYY(3-36) from cattle with a range of 0.10 to 16 pmol/L (BG-BVN11885, Novateinbio, Woburn, MA). Addition of 2.5, 5, and $10 \mathrm{pmol} / \mathrm{L}$ for PYY to pooled plasma in 3 independent assays yielded mean recoveries of 97,104 , and $96 \%$, respectively. Parallelism was assessed by serial dilutions of bovine plasma (1:2 to 1:16) using a pooled sample. Linear regression of expected versus measured concentrations for PYY yielded average slope of $1.55, \mathrm{R}^{2}$ values $(P<0.001)$ of 0.82 , and Y-intercept of 0.33 . The intraassay and interassay co- 
efficients of variation for PYY were 5.18 and $21.9 \%$, respectively, and assay sensitivity was $1.74 \mathrm{pmol} / \mathrm{L}$.

Plasma adropin concentrations were measured using an assay that cross reacts with human, rat, mouse, and horse adropin (34-76) with a range of 2 to 20,000 pmol/L (EK-032-35, Phoenix Pharmaceuticals Inc., Burlingame, CA). Addition of 200 and 2,000 pmol/L of adropin to pooled plasma in 3 independent assays yielded mean recoveries of 110 and $136 \%$, respectively. Parallelism was assessed by serial dilutions of bovine plasma (1:2 to 1:16) using 2 pooled samples. Linear regression of expected versus measured concentrations for adropin yielded average slope of $1.04, \mathrm{R}^{2}$ values $(P<$ 0.001 ) of 0.97 , and Y-intercept of 0.58 . The intraassay and interassay coefficients of variation for adropin were 12.48 and $11.4 \%$, respectively, and assay sensitivity was $415.73 \mathrm{pmol} / \mathrm{L}$.

Insulin concentrations were measured using a bovine insulin-specific assay with a range of 8.6 to $516 \mathrm{pmol} / \mathrm{L}$ (10-1201-01, Mercodia, Uppsala, Sweden). Plasma leptin concentrations were measured using a bovine leptin specific assay with a range of 195 to $3,125 \mathrm{pmol} / \mathrm{L}$ (CSB-E06771b, Cusabio, Hubei Province, China). Spikes of $259 \mathrm{pmol} / \mathrm{L}$ for insulin and $781 \mathrm{pmol} / \mathrm{L}$ for leptin in 3 independent assays yielded mean recoveries of 98 and $73 \%$, respectively. The intraassay coefficients of variation for insulin and leptin were 3.09 and $3.37 \%$, interassay coefficients of variation were 9.9 and $7.0 \%$, and assay sensitivities were 33.07 and $355.69 \mathrm{pmol} / \mathrm{L}$, respectively. Plasma NEFA (NEFA-C, Wako Chemicals USA Inc., Richmond, VA), BHBA (Roche Diagnostics, Indianapolis, IN), and glucose (P7119, Sigma-Aldrich) were determined using commercially available kits.

\section{Statistical Analyses}

Measurements of DMI and energy balance were averaged weekly before analyses. Repeated measurements on plasma hormones, NEFA, BHBA, glucose, DMI, BW, BCS, and energy balance were analyzed using the MIXED procedure of SAS (Ver. 9.3 SAS Institute Inc., Cary, NC) after modeling the covariance matrix structure using compound symmetry. The final statistical model for hormones included fixed effects of dietary treatment, sampling time, physiological stage, parity, treatment $\times$ time, treatment $\times$ stage, time $\times$ stage, and treatment $\times$ time $\times$ stage. Because parity was not significant, the associated interactions with other fixed effects were removed from the model. Insulin data were log-transformed before analyses. Metabolites, DMI, BW, BCS, and energy balance were analyzed using a similar model but without the effects of time. The cow within treatment was considered as the random effect. The PDIFF procedure was applied to separate the means. To study the association of hormones with DMI, BW, BCS, energy balance, and metabolites, the periprandial hormone concentrations were averaged, and then Pearson correlation analysis was conducted separately for prepartum and postpartum variables. Furthermore, linear regression of $\mathrm{BW}$ on individual hormones within each treatment was performed and the slopes compared between treatments. All data are reported as least squares means $\pm \mathrm{SE}$. Significance was declared at $P \leq 0.05$ and trends at $0.05<P<0.10$.

\section{RESULTS}

The effects of physiological stage $(P<0.05)$ on multiple parameters were significant. During the postpartum period, plasma NEFA $(P<0.01)$ and BHBA $(P$ $<0.05)$ concentrations were increased, whereas plasma glucose $(P<0.01)$, BW $(P<0.01)$, BCS $(P<0.01)$, and energy balance $(P<0.01)$ were decreased. Although treatments did not differ with regard to energy balance, milk yield, BW, and BCS, treatment effects on DMI were significant $(P=0.05)$. The cows on the CAN treatment consumed less $(P=0.02)$, and SUN cows tended $(P=0.08)$ to have lower DMI, than CON cows prepartum (Table 2); however, postpartum DMI did not differ between treatments. Parity had a significant effect on NEFA, BHBA, glucose, DMI, milk yield, and energy balance $(P<0.05)$. Plasma concentrations of NEFA (primiparous vs. multiparous: $193 \pm 42$ vs. 309 $\pm 25 \mathrm{mEq} / \mathrm{dL})$ and BHBA (10 \pm 1.1 vs. $13 \pm 0.6 \mathrm{mg} /$ $\mathrm{dL})$, DMI (13 \pm 0.5 vs. $15 \pm 0.3 \mathrm{~kg} / \mathrm{d})$, and milk yield $(24 \pm 2.4$ vs. $39 \pm 1.3 \mathrm{~kg} / \mathrm{d})$ were greater in multiparous than primiparous cows. However, plasma glucose concentrations $(61 \pm 2.3$ vs. $53 \pm 1.4 \mathrm{mg} / \mathrm{dL})$ and energy balance $(1.16 \pm 1.13$ vs. $-1.85 \pm 0.67 \mathrm{Mcal} / \mathrm{d})$ were greater in primiparous than multiparous cows $(P$ $<0.01)$. No significant effects existed of parity on BW, BCS, and hormones $(P>0.10)$.

We observed significant effects of stage $(P<0.01)$ on plasma GLP-1 concentrations, with postpartum concentrations being $40 \%$ greater than prepartum concentrations (Figure 1A). However, there was no evidence for any treatment effect, or meal responses, on plasma GLP-1 concentrations. Stage significantly affected $(P=0.05)$ and the treatment $\times$ stage interaction tended to affect $(P=0.06)$ plasma PYY concentrations (Figure 1B). Overall plasma PYY concentrations were $6 \%$ greater $(P<0.05)$ postpartum than prepartum. Although no apparent meal response existed and treatments did not differ $(P>0.05)$, plasma PYY concentrations were $20 \%$ lower prepartum than postpartum in the CAN group $(P=0.004)$. 


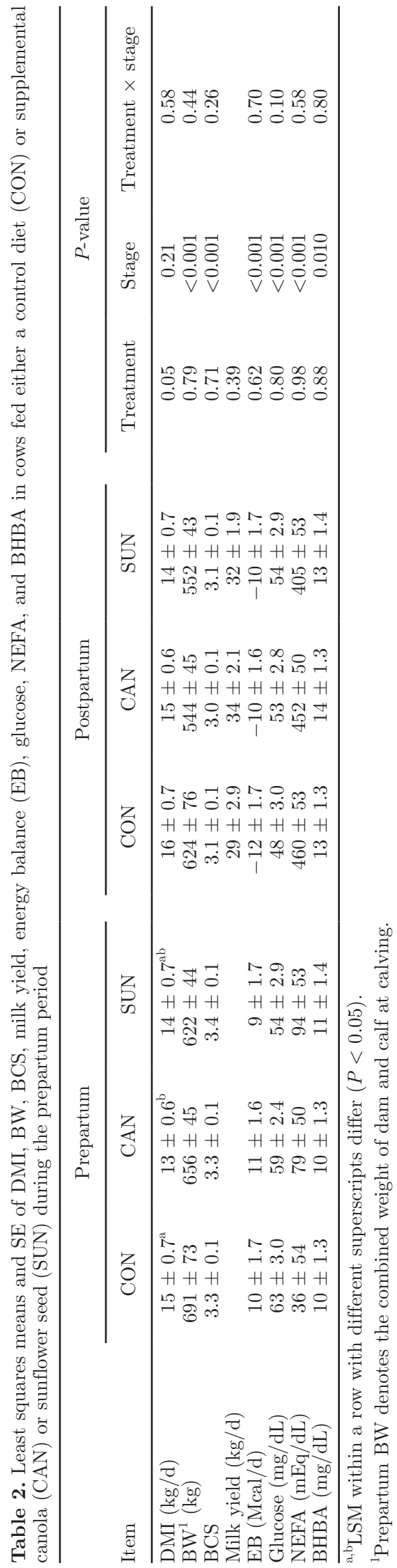

Stage $(P<0.01)$ and treatment $\times$ stage interactions $(P=0.009)$ had significant effects on plasma adropin concentrations, and time $(P=0.10)$ tended to affect plasma adropin concentrations (Figure 1C). Overall adropin concentrations were significantly higher by $17 \%$ postpartum than prepartum, with a $41 \%$ increase particularly in CON $(P<0.01)$ relative to CAN and SUN groups. Postprandial adropin concentrations at $+2 \mathrm{~h}(P=0.04)$ were higher than preprandial concentrations at $-2 \mathrm{~h}$.

Time $(P<0.01)$, stage $(P<0.01)$, and time $\times$ stage interactions $(P<0.01)$ had significant effects on plasma insulin concentrations (Figure 1D). Across treatments, insulin concentrations were significantly higher prepartum than postpartum. Prepartum insulin concentrations at $-2 \mathrm{~h},+2 \mathrm{~h}$, and $+14 \mathrm{~h}$ were 90,152 , and $105 \%$ higher than postpartum concentrations, respectively. Postprandial insulin concentrations at $+2 \mathrm{~h}$ $(P<0.01)$ and $+14 \mathrm{~h}(P<0.01)$ were also significantly higher than preprandial concentrations $(-2 \mathrm{~h})$ during the prepartum period across treatments. Postpartum plasma insulin concentrations tended $(P=0.07)$ to be increased only at $+14 \mathrm{~h}$ compared with $-2 \mathrm{~h}$ but did not differ $(P>0.10)$ at other time points.

There were significant effects of stage $(P<0.01)$ and time $\times$ stage interaction $(P=0.04)$ and weak trends for time $(P=0.10)$ and treatment $\times$ stage interaction $(P=0.08)$ on plasma leptin concentrations (Figure 1E). Across treatments, leptin concentrations were significantly higher by $2 \%$ prepartum compared with postpartum. Postpartum plasma leptin concentrations were reduced by 2 and $4 \%$ at $-2 \mathrm{~h}(P=0.02)$ and $+2 \mathrm{~h}$ $(P<0.01)$, respectively. Postprandial leptin concentrations at $+2 \mathrm{~h}(P=0.06)$ and $+14 \mathrm{~h}(P=0.07)$ also tended to be higher than preprandial concentrations at $-2 \mathrm{~h}$. Leptin concentrations decreased in CAN $(P=$ $0.04)$ by $2 \%$ and in CON $(P<0.01)$ by $4 \%$ postpartum.

During the prepartum period, despite strong positive correlations of BW with GLP-1 and adropin, none of the variables were significantly correlated (Table 3 ). During the postpartum period, a significant strong negative correlation was observed between PYY and BW $(P=0.03)$, and between insulin and NEFA $(P=$ $0.02)$ and BHBA $(P<0.01)$. The remaining variables were poorly correlated. Furthermore, the slopes for the regression of BW on GLP-1 during the prepartum ( $P$ $=0.69)$ and postpartum $(P=0.95)$ periods were not different. Similarly, the slopes for the regression of BW on insulin prepartum $(P=0.26)$ and postpartum $(P=$ $0.20)$, on leptin prepartum $(P=0.15)$ and postpartum $(P=0.97)$, and on adropin prepartum $(P=0.06)$ and postpartum $(P=0.30)$ also did not differ. However, the slopes for the regression of BW on PYY were signifi- 

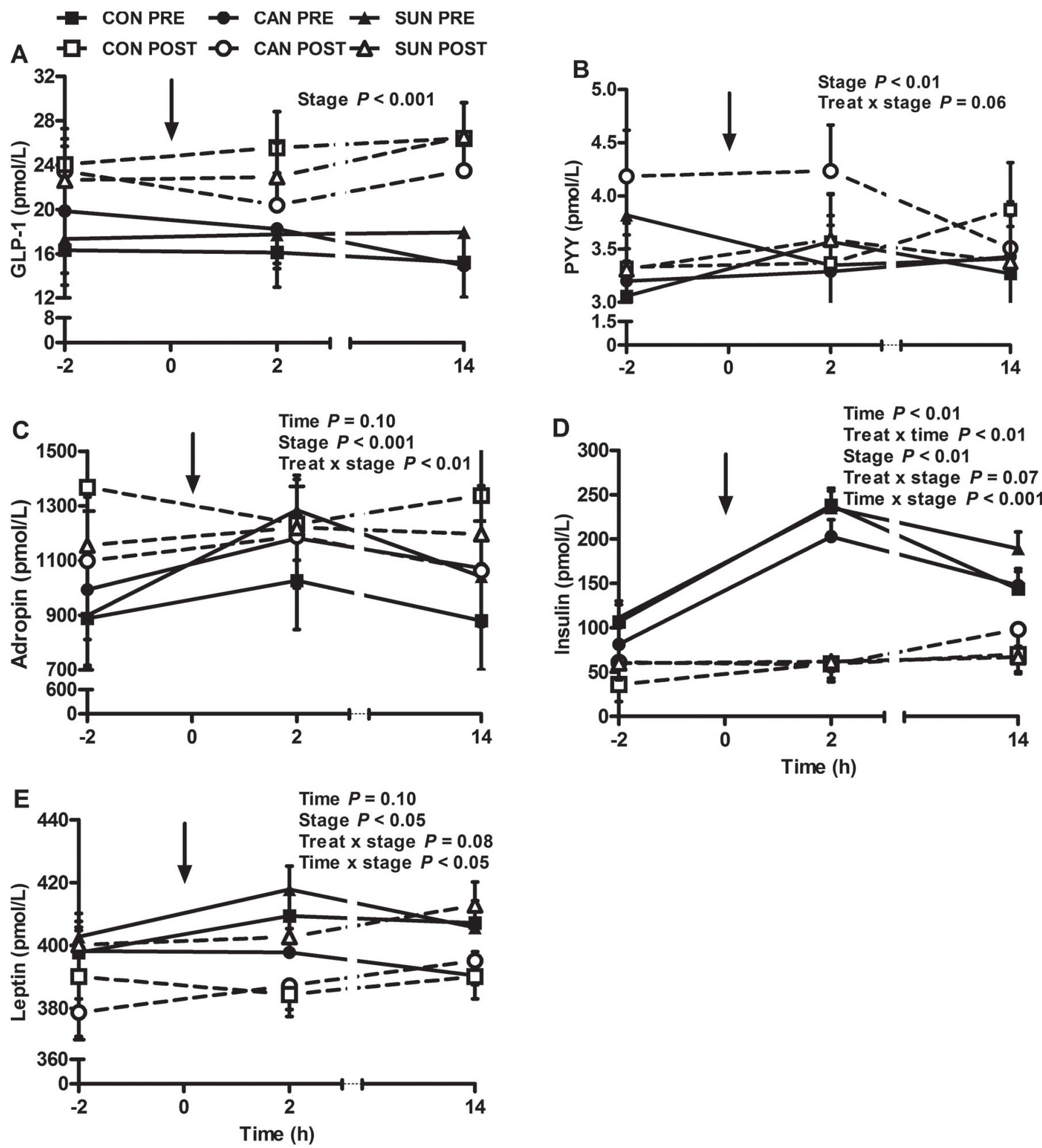

Figure 1. Plasma concentrations of glucagon-like peptide-1 (GLP-1; A), peptide tyrosine-tyrosine (PYY; B), adropin (C), insulin (D), and leptin (E) in dairy cows. The cows were supplemented with rolled canola (CAN; $\bigcirc$, $\bullet$ ) or sunflower (SUN; $\Delta$, $\boldsymbol{\Delta}$ ) seed or were fed a control $(\mathrm{CON} ; \square, \boldsymbol{\square})$ no-oilseed diet, during the prepartum period followed by a common lactation diet. Blood samples were collected from the tail vein at $-2,+2$ and $+14 \mathrm{~h}$ relative to feeding from all cows at $2 \mathrm{wk}$ after the introduction of the diets prepartum (PRE; filled symbols) and again at 2 wk postpartum (POST; clear symbols). Arrows indicate the time of feeding. The $P$-values for fixed effects of dietary treatment (Treat), physiological stage, time, and their interactions are shown. Data are least squares means \pm standard error. 
cantly different prepartum $(P=0.006)$ and tended to be significant postpartum $(P=0.06)$.

\section{DISCUSSION}

Although one of the goals of prepartum dietary fat supplementation is to increase energy intake and attenuate the degree of negative energy balance postpartum, dietary lipids often lead to reduction in DMI. However, little is known of the underlying hormonal and metabolic adaptations following prepartum dietary fat supplementation. We evaluated the effects of prepartum diets containing rolled canola, sunflower, or control (no oilseed) on circulating concentrations of key hormones involved in nutrient digestion and regulation of feed intake-GLP-1, PYY, adropin, insulin, and leptin. Our results highlight several important findings. First, dietary supplementation with canola or sunflower seeds alone did not affect energy balance; BW; and plasma metabolite and GLP-1, PYY, insulin, leptin, and adropin concentrations prepartum. We speculate that prepartum changes in these hormones are unlikely to have played a role in the hypophagic effects of canola and sunflower in our study. Second, the physiological stage had a significant, but divergent, effect on circulating hormone and metabolite concentrations as well as energy-balance parameters. Plasma GLP-1, PYY, adropin, NEFA, and BHBA concentrations were greater postpartum than prepartum, whereas glucose, insulin, leptin, BW, BCS, and energy balance were greater prepartum than postpartum. Third, with the exception of GLP-1, the treatment $\times$ stage interactions were significant for leptin and adropin and tended to significance for PYY and insulin. Fourth, only insulin concentrations were increased after feeding prepartum, whereas none of the other hormones showed a consistent meal response. And fifth, postpartum PYY concentrations were strongly and negatively correlated with BW, suggesting that PYY may be associated with
BW regulation during the transition period. Together, these novel findings demonstrate that the physiological stage is a more important determinant of circulating gut hormones than dietary lipid in transition dairy cows.

Prepartum dietary lipid supplementation did not affect energy balance, BW, or BCS in the current study. However, prepartum DMI was significantly decreased with CAN and tended to decrease with SUN treatments. These findings are in general agreement with some (Moallem et al., 2007; Duske et al., 2009; Karimian et al., 2015) but not all (Afzalzadeh et al., 2010; Hayirli et al., 2011) reports of reduced DMI with prepartum fat supplementation. The inconsistencies among studies could likely be due to the amount and types of fat sources. Though we formulated the fat supplements to be isocaloric, on analyses, the CAN diet had marginally greater lipid content than the SUN diet, which might have contributed to the more robust effect of the CAN diet in decreasing DMI. However, less is known of the mechanisms by which prepartum lipid decreases DMI.

In the current study, dietary CAN or SUN $(\sim 8 \%$ of DM) did not affect plasma GLP-1 concentrations despite reductions in DMI. We also did not observe a postprandial increase in plasma GLP-1 concentrations, which is likely due to a relatively constant rate of delivery of nutrients to the lower intestines in these ad libitum-fed cows. In previous studies with midlactation dairy cows, dietary supplementation with rumen-protected fat (calcium salts of palm distillate or soybean oil) at $\sim 2.5$ to $3.5 \%$ of ration $\mathrm{DM}$ for $\sim 2$ to 3 wk has been reported to increase plasma concentrations of GLP-1 coincident with a reduction in DMI (Relling and Reynolds, 2007a; Bradford et al., 2008), whereas supplementation at $1.5 \%$ of $\mathrm{DM}$, for similar duration, has been shown to decrease DMI and plasma GLP-1 concentrations (Fukumori et al., 2012). Abomasal infusion of unsaturated fat from canola or soybean oil has been shown to more consistently increase plasma

Table 3. Correlation coefficients between plasma hormone ${ }^{1}$ concentrations and DMI, BW, BCS, energy balance, and plasma metabolites

\begin{tabular}{|c|c|c|c|c|c|c|c|c|c|c|}
\hline \multirow[b]{2}{*}{ Item } & \multicolumn{5}{|c|}{ Prepartum } & \multicolumn{5}{|c|}{ Postpartum } \\
\hline & GLP-1 & PYY & $\mathrm{ADR}$ & INS & LEP & GLP-1 & PYY & $\mathrm{ADR}$ & INS & LEP \\
\hline BW & 0.34 & -0.26 & 0.37 & 0.16 & -0.29 & 0.17 & $-0.48^{*}$ & 0.27 & -0.12 & -0.19 \\
\hline BCS & -0.03 & -0.27 & -0.29 & -0.07 & -0.08 & -0.24 & 0.05 & -0.19 & 0.26 & -0.12 \\
\hline Energy balance & -0.11 & -0.28 & -0.19 & 0.09 & -0.21 & -0.08 & -0.12 & -0.36 & 0.31 & 0.28 \\
\hline Glucose & -0.21 & 0.02 & -0.24 & -0.06 & -0.09 & 0.30 & 0.01 & 0.01 & 0.20 & 0.37 \\
\hline
\end{tabular}

${ }^{1}$ GLP-1 = glucagon-like peptide-1; PYY = peptide tyrosine-tyrosine; ADR = adropin; INS = insulin; LEP = leptin.

$* P<0.05$. 
GLP-1 concentrations and decrease DMI in lactating dairy cows (Relling and Reynolds, 2007b, 2008). Therefore, the lack of effects of dietary lipid on prepartum GLP-1 concentrations in our study might be due to the physiological stage (pregnant vs. lactating), the type of fat (rolled oilseeds in our study vs. rumen-protected fat supplements in other studies), or the dose of fat supplemented. Despite lack of effects of dietary lipid, we observed an increase in plasma GLP-1 concentrations postpartum. Our findings are consistent with a previous report of increased postpartum GLP-1 concentrations in dairy cows (Relling and Reynolds, 2007b). It remains to be determined whether the increased postpartum GLP-1 concentrations are due to increased secretion secondary to gut hypertrophy and hyperplasia, or due to reduced clearance. We previously observed that GLP-1 receptor is expressed in high abundance in the gut with relatively lower expression in the pancreas, kidney, and spleen (Pezeshki et al., 2012). Though the GLP-1 receptor signaling remains to be determined in these tissues, it is likely that the increased postpartum GLP-1 concentrations may modulate gut motility and pancreatic secretions to meet the digestive and metabolic demands of early lactation.

We previously reported that transcripts for enteroglucagon (which encodes for GLP-1 in the intestine) and PYY show similar distribution pattern with abundant mRNA expression in the lower intestinal segments of cattle (Pezeshki et al., 2012). For the first time, we now provide evidence of alterations in plasma PYY concentrations during the periparturient period in dairy cows. We observed a significant increase in plasma PYY concentrations postpartum than prepartum across treatments. Interestingly, plasma PYY concentrations with the CAN treatment were particularly decreased prepartum compared with postpartum, coincident with a prepartum reduction in DMI, suggesting that PYY concentrations might be sensitive to changes in DMI. Though the underlying mechanisms of differential treatment effects on PYY secretion remain to be determined, the absence of a distinct prepartum increase in plasma PYY and GLP-1 concentrations suggests that it is unlikely that prepartum alterations of these hormones play a role in the hypophagic effects of CAN and SUN diets in this study. The postpartum PYY concentrations exhibited a strong negative correlation with BW, suggesting that circulating PYY concentrations may be associated with BW regulation during the transition period. The increased postpartum PYY concentrations are consistent with similar findings of increased concentrations during early lactation in rats (Taylor et al., 2009; Suzuki et al., 2014). Similar to our GLP-1 results, we also did not detect any meal-induced responses in the plasma concentrations of PYY. Although plasma PYY concentrations in our study are within the range of levels reported in sheep $(\sim 5-10$ $\mathrm{pmol} / \mathrm{L}$ ), in contrast to our findings, ingestion of highfiber or high-concentrate diets, or ileal infusion of oleic acid, butyric acid, casein, or maltose, failed to increase plasma PYY concentrations in male sheep (Onaga et al., 2000). It is unclear whether this is due to differences in species, sex, physiological stage, or dose of nutrients administered. Unlike the GLP-1 receptor distribution, we previously observed that the PYY $\mathrm{Y}_{2}$ receptors are highly expressed and restricted primarily to the gut in cattle (Pezeshki et al., 2012). Therefore, it is likely that increased postpartum plasma PYY concentrations may play a role in modulating gut motility and secretions to adapt for the increased demands of lactation.

To our knowledge, this is the first report of changes in adropin concentrations during the transition from pregnancy to lactation in ruminants. Interestingly, plasma concentrations of adropin were strongly influenced by stage and treatment $\times$ stage interactions. Adropin concentrations were greater postpartum than prepartum, whereas the concentrations were increased after feeding prepartum but not postpartum. Consistent with our findings, plasma adropin concentrations were reported to be increased in lactating women compared with nonpregnant, nonlactating women (Aydin et al., 2013). We were unable to detect an increase in plasma adropin concentrations in cows fed oilseeds prepartum despite an apparent postprandial increase across treatments. In contrast to our findings, high-fat feeding (60\% fat, $6 \%$ soybean oil, and $54 \%$ lard) was reported to stimulate adropin expression and secretion in rats (Kumar et al., 2008). Thus, discrepancies among studies could likely be due to differences between species, physiological stage, or level of fat inclusion (60\% fat in rats compared with $8 \%$ oilseeds in our cows).

As expected, and consistent with other reports (Block et al., 2003; Reist et al., 2003; Kokkonen et al., 2005), plasma concentrations of leptin and insulin were lower postpartum than prepartum, reflecting the states of negative and positive energy balances, respectively. Furthermore, both hormones increased after feeding prepartum but not postpartum. The lower postpartum insulin concentrations together with a strong negative correlation of insulin with NEFA and BHBA are supportive of decreased lipogenesis during this period.

In summary, prepartum dietary canola and sunflower seed supplementation produces marginal effects on most of the hormones and metabolites in transition dairy cows. Although the changes in plasma concentrations of insulin, GLP-1, and leptin are in general consistent with previous reports, for the first time we 
provide plasma profiles of PYY and adropin during the transition period. However, a potential limitation of our study is that the sampling protocol is limited to 2 windows during the pre- and postpartum periods; whether concentrations of the hormones measured in this study, and their specific isoforms, are responsive to dietary lipid content and composition at other times remains to be determined. Regardless, our results demonstrate that rather than dietary lipid content, the main driver of changes in circulating concentrations of gut hormones is the transition from pregnancy to lactation. A causative role for GLP-1, PYY, and adropin in the regulation of energy balance and metabolism during the transition period remains to be established.

\section{ACKNOWLEDGMENTS}

The work was supported by the University of Calgary Margaret Gunn Endowment for Animal Research (MGEAR), and Natural Sciences and Engineering Research Council of Canada (NSERC) Discovery grant (Application ID 355993-2013) to Prasanth K. Chelikani, and by grants from Alberta Innovates BioSolutions, Alberta Livestock and Meat Agency, and Alberta Milk to Divakar J. Ambrose. Support was also received from Livestock Research Branch, Alberta Agriculture and Rural Development. We gratefully acknowledge Masahito Oba (University of Alberta) for designing the rations for this study. We appreciate the assistance of Marcos Colazo and Ana Ruiz-Sanchez with sample collections, and staff at the Dairy Research and Technology Centre, University of Alberta, for the feeding and care of the experimental animals.

\section{REFERENCES}

Afzalzadeh, A., M. H. Palizdar, H. Mahmoudzadeh, and A. NiasariNaslaji. 2010. Effect of fat supplementation during transition period on plasma leptin and non-esterified fatty acid concentrations in Holstein cows. Anim. Sci. J. 81:309-315.

Aydin, S., T. Kuloglu, and S. Aydin. 2013. Copeptin, adropin and irisin concentrations in breast milk and plasma of healthy women and those with gestational diabetes mellitus. Peptides 47:66-70.

Block, S. S., J. M. Smith, R. A. Ehrhardt, M. C. Diaz, R. P. Rhoads, M. E. Van Amburgh, and Y. R. Boisclair. 2003. Nutritional and developmental regulation of plasma leptin in dairy cattle. J. Dairy Sci. 86:3206-3214

Bradford, B. J., K. J. Harvatine, and M. S. Allen. 2008. Dietary unsaturated fatty acids increase plasma glucagon-like peptide-1 and cholecystokinin and may decrease premeal ghrelin in lactating dairy cows. J. Dairy Sci. 91:1443-1450.

CCAC. 1993. Guide to the Care and Use of Experimental Animals. Canadian Council on Animal Care. Vol. 1. 2 ed. CCAC, Ottawa, Ontario, Canada.

Chelikani, P. K., D. R. Glimm, D. H. Keisler, and J. J. Kennelly. 2004 Effects of feeding or abomasal infusion of canola oil in Holstein cows. 2. Gene expression and plasma concentrations of cholecystokinin and leptin. J. Dairy Res. 71:288-296.
Colazo, M. G., A. Hayirli, L. Doepel, and D. J. Ambrose. 2009. Reproductive performance of dairy cows is influenced by prepartum feed restriction and dietary fatty acid source. J. Dairy Sci. $92: 2562-2571$

Dong, C. X., and P. L. Brubaker. 2012. Ghrelin, the proglucagonderived peptides and peptide YY in nutrient homeostasis. Nat. Rev. Gastroenterol. Hepatol. 9:705-715.

Drackley, J. K. 1999. ADSA Foundation Scholar Award. Biology of dairy cows during the transition period: the final frontier? J. Dairy Sci. 82:2259-2273.

Duske, K., H. M. Hammon, A. K. Langhof, O. Bellmann, B. Losand, K. Nurnberg, G. Nurnberg, H. Sauerwein, H. M. Seyfert, and C. C. Metges. 2009. Metabolism and lactation performance in dairy cows fed a diet containing rumen-protected fat during the last twelve weeks of gestation. J. Dairy Sci. 92:1670-1684.

Edmonson, A. J.. I. J. Lean, L. D. Weaver, L. Farver, and G. Webster. 1989. A body condition scoring chart for Holstein dairy cows. J. Dairy Sci. 72:68-78.

Fukumori, R., T. Sugino, H. Shingu, N. Moriya, Y. Hasegawa, M. Kojima, K. Kangawa, T. Obitsu, S. Kushibiki, and K. Taniguchi. 2012. Effects of calcium salts of long-chain fatty acids and rumen-protected methionine on plasma concentrations of ghrelin, glucagon-like peptide-1 (7 to 36) amide and pancreatic hormones in lactating cows. Domest. Anim. Endocrinol. 42:74-82.

Goff, J. P., and R. L. Horst. 1997. Physiological changes at parturition and their relationship to metabolic disorders. J. Dairy Sci 80:1260-1268.

Hayirli, A., D. H. Keisler, L. Doepel, and H. Petit. 2011. Peripartum responses of dairy cows to prepartal feeding level and dietary fatty acid source. J. Dairy Sci. 94:917-930.

Karimian, M., M. Khorvash, M. A. Forouzmand, M. Alikhani, H. R. Rahmani, M. H. Ghaffari, and H. V. Petit. 2015. Effect of prepartal and postpartal dietary fat level on performance and plasma concentration of metabolites in transition dairy cows. J. Dairy Sci. 98:330-337.

Karra, E., and R. L. Batterham. 2010. The role of gut hormones in the regulation of body weight and energy homeostasis. Mol. Cell. Endocrinol. 316:120-128.

Kokkonen, T., J. Taponen, T. Anttila, L. Syrjala-Qvist, C. Delavaud, Y. Chilliard, M. Tuori, and A. T. Tesfa. 2005. Effect of body fatness and glucogenic supplement on lipid and protein mobilization and plasma leptin in dairy cows. J. Dairy Sci. 88:1127-1141.

Kumar, K. G., J. L. Trevaskis, D. D. Lam, G. M. Sutton, R. A. Koza, V. N. Chouljenko, K. G. Kousoulas, P. M. Rogers, R. A. Kesterson, M. Thearle, A. W. Ferrante Jr., R. L. Mynatt, T. P. Burris, J. Z. Dong, H. A. Halem, M. D. Culler, L. K. Heisler, J. M. Stephens, and A. A. Butler. 2008. Identification of adropin as a secreted factor linking dietary macronutrient intake with energy homeostasis and lipid metabolism. Cell Metab. 8:468-481.

Larsen, M., A. E. Relling, C. K. Reynolds, and N. B. Kristensen. 2010. Effect of abomasal glucose infusion on plasma concentrations of gut peptides in periparturient dairy cows. J. Dairy Sci 93:5729-5736.

Liefers, S. C., R. F. Veerkamp, M. F. Te Pas, C. Delavaud, Y. Chilliard, and T. van der Lende. 2003. Leptin concentrations in relation to energy balance, milk yield, intake, live weight, and estrus in dairy cows. J. Dairy Sci. 86:799-807.

Loften, J. R., J. G. Linn, J. K. Drackley, T. C. Jenkins, C. G. Soderholm, and A. F. Kertz. 2014. Invited review: palmitic and stearic acid metabolism in lactating dairy cows. J. Dairy Sci. 97:46614674.

Moallem, U., M. Katz, A. Arieli, and H. Lehrer. 2007. Effects of peripartum propylene glycol or fats differing in fatty acid profiles on feed intake, production, and plasma metabolites in dairy cows. J. Dairy Sci. 90:3846-3856.

National Research Council. 2001. Nutrient Requirements of Dairy Cattle. 7th Ed. Natl. Acad. Sci., Washington, DC.

Onaga, T., M. Yoshida, H. Inoue, and H. Yokota. 2000. Regional distribution and plasma concentration of peptide YY in sheep. Peptides 21:655-667. 
Petit, H. V., M. F. Palin, and L. Doepel. 2007. Hepatic lipid metabolism in transition dairy cows fed flaxseed. J. Dairy Sci. 90:47804792.

Pezeshki, A., G. P. Muench, and P. K. Chelikani. 2012. Short communication: expression of peptide YY, proglucagon, neuropeptide Y receptor Y2, and glucagon-like peptide-1 receptor in bovine peripheral tissues. J. Dairy Sci. 95:5089-5094.

Rabelo, E., R. L. Rezende, S. J. Bertics, and R. R. Grummer. 2003. Effects of transition diets varying in dietary energy density on lactation performance and ruminal parameters of dairy cows. J. Dairy Sci. 86:916-925.

Reist, M., D. Erdin, D. von Euw, K. Tschuemperlin, H. Leuenberger, C. Delavaud, Y. Chilliard, H. M. Hammon, N. Kuenzi, and J. W. Blum. 2003. Concentrate feeding strategy in lactating dairy cows metabolic and endocrine changes with emphasis on leptin. J. Dairy Sci. 86:1690-1706.

Relling, A. E., and C. K. Reynolds. 2007a. Feeding rumen-inert fats differing in their degree of saturation decreases intake and increases plasma concentrations of gut peptides in lactating dairy cows. J. Dairy Sci. 90:1506-1515.
Relling, A. E., and C. K. Reynolds. 2007b. Plasma concentrations of gut peptides in dairy cattle increase after calving. J. Dairy Sci. 90:325-330.

Relling, A. E., and C. K. Reynolds. 2008. Abomasal infusion of casein, starch and soybean oil differentially affect plasma concentrations of gut peptides and feed intake in lactating dairy cows. Domest. Anim. Endocrinol. 35:35-45.

Staples, C. R., J. M. Burke, and W. W. Thatcher. 1998. Influence of supplemental fats on reproductive tissues and performance of lactating cows. J. Dairy Sci. 81:856-871.

Suzuki, Y., K. Nakahara, K. Maruyama, R. Okame, T. Ensho, Y. Inoue, and N. Murakami. 2014. Changes in mRNA expression of arcuate nucleus appetite-regulating peptides during lactation in rats. J. Mol. Endocrinol. 52:97-109.

Taylor, V. J., M. Patterson, M. A. Ghatei, S. R. Bloom, and C. A Wilson. 2009. Ghrelin and peptide YY (PYY) profiles in gastrointestinal tissues and the circulation of the rat during pregnancy and lactation. Peptides 30:2213-2220. 